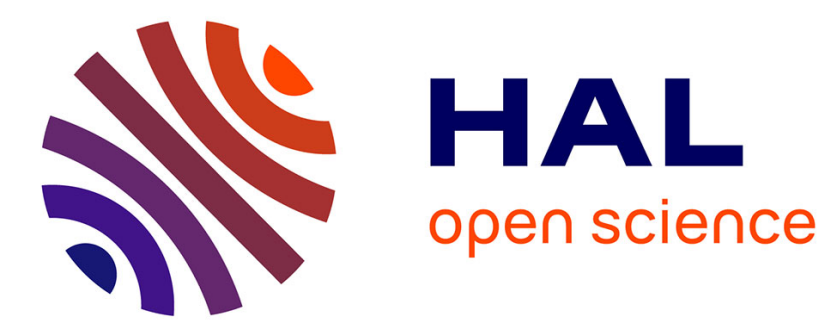

\title{
Non-equilibrium Nitrogen Re-entry Flow Computed with a Vibrational-Specific Kinetics Model
}

Marie-Claude Druguet, Arnaud Bultel, Vincent Morel, Julien Annaloro

\section{To cite this version:}

Marie-Claude Druguet, Arnaud Bultel, Vincent Morel, Julien Annaloro. Non-equilibrium Nitrogen Re-entry Flow Computed with a Vibrational-Specific Kinetics Model. AIAA SciTech 2019 Forum, Jan 2019, San Diego, CA, United States. 10.2514/6.2019-2283 . hal-03575424

\section{HAL Id: hal-03575424 \\ https://hal.science/hal-03575424}

Submitted on 15 Feb 2022

HAL is a multi-disciplinary open access archive for the deposit and dissemination of scientific research documents, whether they are published or not. The documents may come from teaching and research institutions in France or abroad, or from public or private research centers.
L'archive ouverte pluridisciplinaire HAL, est destinée au dépôt et à la diffusion de documents scientifiques de niveau recherche, publiés ou non, émanant des établissements d'enseignement et de recherche français ou étrangers, des laboratoires publics ou privés. 


\title{
Non-equilibrium Nitrogen Re-entry Flow Computed with a Vibrational-Specific Kinetics Model
}

\author{
Marie-Claude Druguet* \\ Aix-Marseille Univ., Marseille, France, 13453 \\ Arnaud Bultel ${ }^{\dagger}$ and Vincent Morel ${ }^{*}$ \\ Normandy University, St Etienne du Rouvray, 76801, France \\ Julien Annaloro ${ }^{\S}$ \\ CNES, Toulouse, France, 31401
}

\begin{abstract}
The present work assesses the feasibility of implementing a collisional-radiative model into a CFD code and obtaining flow-field results in reasonable computational times. A major step towards this goal is to implement a state-specific vibrational model for Nitrogen into a Navier-Stokes code, to produce aero-thermodynamic flow-fields, namely fields of vibrationalstate population densities and of temperatures, in the shock layer past a blunt body flying at atmospheric-entry conditions. The paper presents the equations, the vibrational-specific kinetics model, the methodology, a description of the CFD code PINENS, and the results then obtained. Spatial evolution of the chemical species on their vibrational excited states in an axisymmetric shock layer flow resolved by the PINENS code, as well as Boltzmann distributions of the population densities on the vibrational levels, are presented. Comparisons between results obtained with detailed models and results obtained with global models are discussed and show how the global models perform compared to the detailed models in the prediction of the chemical species and vibrational states evolution in a shock layer.
\end{abstract}

\section{Nomenclature}

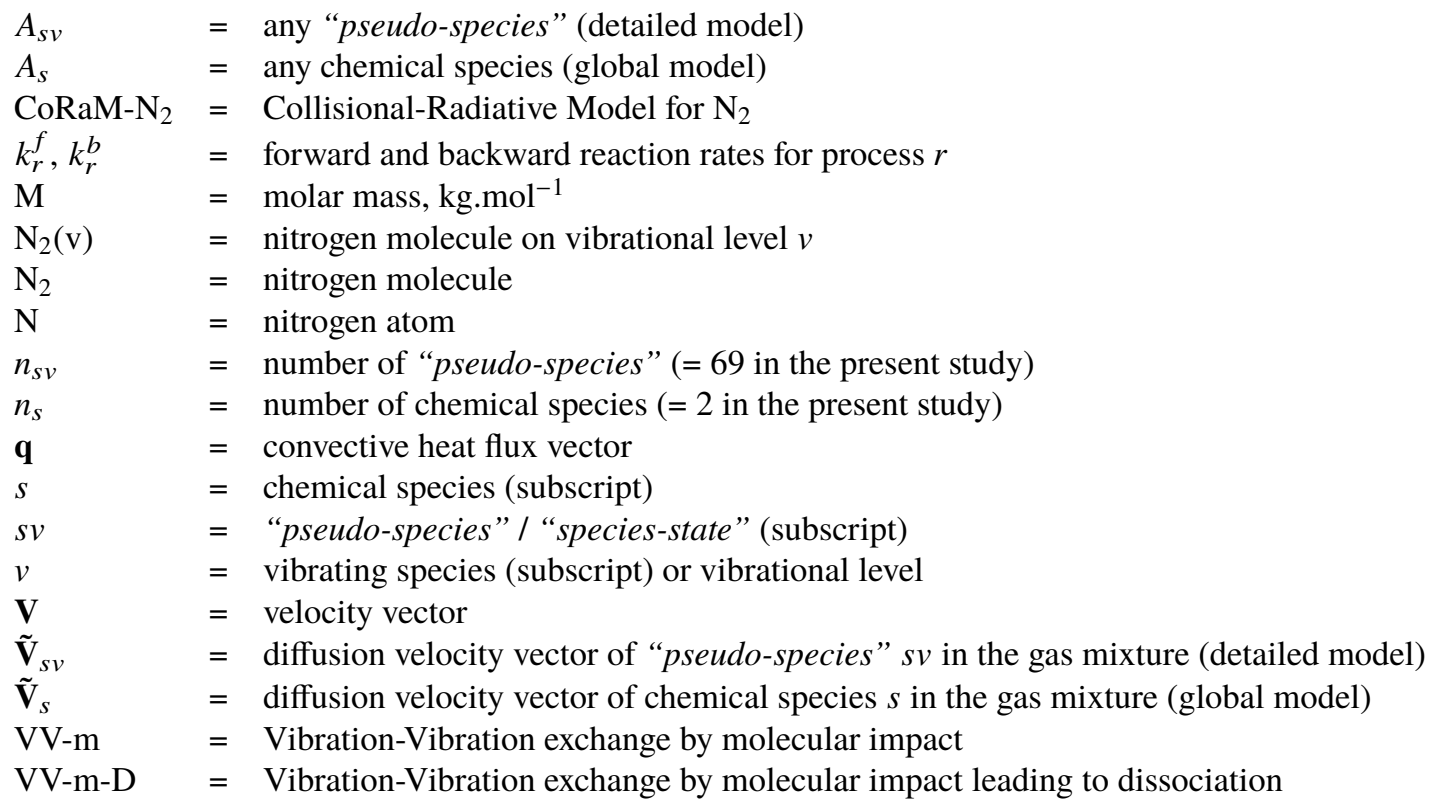

\footnotetext{
*CNRS Research Scientist, UMR CNRS 7343 IUSTI, 5 rue Enrico Fermi. marie-claude.druguet@univ-amu.fr

$\dagger$ Associate Professor, UMR CNRS 6614 CORIA, Site du Madrillet. arnaud. bultel@coria. fr

Assistant Professor, UMR CNRS 6614 CORIA, Site du Madrillet.

${ }^{\S}$ Research Engineer, DCT/TV/PR, BPI 1717, 18 Avenue Edouard Belin.
} 


$\begin{array}{ll}\text { VT-m } & =\text { Vibration-Translation exchange by molecular impact } \\ \text { VT-m-D } & =\text { Vibration-Translation exchange by molecular impact leading to dissociation } \\ \text { VT-a } & =\text { Vibration-Translation exchange by atomic impact } \\ \text { VT-a-D } & =\text { Vibration-Translation exchange by atomic impact leading to dissociation } \\ v_{s v}^{\prime}, v_{s v}^{\prime \prime} & =\text { stoechiometric coefficients for "species-state" } s v \text { in process } r \text { (detailed model) } \\ v_{s}^{\prime}, v_{s}^{\prime \prime} & =\text { stoechiometric coefficients for chemical species } s \text { in process } r \text { (global model) } \\ \rho_{s v} & =\text { density of "species-state" } s v \\ \rho_{s} & =\text { density of chemical species } s \\ \rho \mathbf{V} & =\text { momentum } \\ \rho e & =\text { total energy per unit volume } \\ \overline{\bar{\sigma}} & =\text { stress tensor } \\ \theta_{r}^{f}, \theta_{r}^{b} & =\text { characteristic temperatures for forward and backward process } r \\ \omega_{s v}^{C} & =\text { chemical source term for "species-state” } s v \text { (detailed model) } \\ \omega_{s}^{C} & =\text { chemical source term for chemical species } s \text { (global model) } \\ \omega_{v}^{V} & =\text { vibrational energy source term for vibrating species } v \text { (global model) }\end{array}$

\section{Introduction}

$T^{H E}$ formation of the plasma produced during the high-velocity entry phase of a spacecraft is a complex phenomena 1 [1]. The space body decelerates due to the more and more dense atmosphere layers encountered and a strong shock wave gets formed in front of the body. The kinetic energy of the gas is transformed into thermal energy across the shock wave, making the gas strongly heated behind the shock. In the shock layer, the plasma is in a thermo-chemical non-equilibrium state, and strong gradients are encountered both across the shock front and through the boundary layer that develops at the body surface. The energy transfer from the heated gas in the shock layer to the body surface takes place through several processes: among them, a convective heat transfer due to the temperature difference between the heated gas and the body surface, a radiative transfer due to the absorption of a part of the transmitted radiation produced within the plasma, and a catalysis process due to the recombination of the dissociated species at the wall. The common feature of these three contributions lies on the major role played by the excitation of the various modes of specific internal energy (namely the vibrational and the electronic modes). The various excited states, indeed, lead to a different internal energy transfer, as they return to the equilibrium state in different ways, if they do so. Moreover, these excited states are the source of radiation by spontaneous de-excitation. Finally, the energy release to the wall due to catalytic processes depends on the excitation of the incident species and of those desorbed from the wall. The key to sizing relevantly the thermal protection system (TPS) of the entering body requires a detailed knowledge of the physical behavior of the excited species, both in the shock layer gas and at the body surface.

For several decades now, modeling and experimental studies have gained interest in the scientific community to better understand the behavior of excited species in non-equilibrium plasmas, typically for planetary atmospheric entries (among many contributions, see Refs. [2] to [20]). Regarding the modeling approach, studies have been done in two different ways: The first way consists in considering the classical global chemical mechanisms, among them the well-known models developed by Park [21-23]. The modeling consists then in considering the chemical species as a whole without distinguishing their excited states. The population number density of their excited states is then estimated either by assuming a Boltzmann distribution at an excitation temperature (the electron temperature $T_{e}$ or even the translation-rotation temperature $T$ ) or by assuming the quasi-steady state. In the latter assumption, the excited state population density only depends on the local collisional and radiative elementary processes. This global approach is widely used in the scientific community that models the planetary entry flows. On the other hand, a second methodology is based on a complete description of the flow field with considering every (or several) excited states of each particle as independent species.

Although the first approach is widely used because it is compatible with numerical computations of multi-dimension flows modeled with the Navier-Stokes equations, it suffers from several weaknesses. First, the reverse rate (for a global reaction like recombination for example) is often computed as the ratio between the forward rate (dissociation) and the equilibrium constant. If this is true for elementary processes as the result of micro-reversibility due to the time-reversal symmetry at colliding particle scale, it is no longer valid at the scale of whole species. Second, the forward rates have often been determined experimentally for a specific situation (strong flow compression for example), but then they are used in a completely different situation (flow expansion). Using these rates for numerically predicting an entire flow-field - where compression and expansion zones are present - leads to a failing in the prediction of the degree 
of recombination in the expansion zone. Third, most of the global rates usually used for reentry flow computations have been determined experimentally in the $60 \mathrm{~s}$ and $70 \mathrm{~s}$, without being updated with using recent databases for the elementary cross-sections renewed during the last decade [11, 14, 17].

If the second approach based on considering each excited state for every species is very attractive because of its expected accuracy in giving a detailed description of a plasma, it is very challenging to implement in CFD codes for several reasons. First, it requires a large amount of computational resources for predicting the multidimensional flow-field around a body entering a planetary atmosphere. Second, it requires specific data for determining the rates for the elementary processes. For the past two decades, however, numerous studies have contributed to supply the databases with new data [11, 16, 17]. Regarding the challenge of computational resources, the high-performance computers now available allow to consider investigating plasma flows in multidimensional configurations with the detailed approach.

In this framework, the present study is an original contribution to computing a reactive and non-equilibrium gas flow through the shock layer surrounding an axi-symmetric blunt body, with detailed collisional-radiative models. If simulating multi-dimension, high-temperature, high-enthalpy, non-equilibrium gas flows in shock layers has been widely done so far with global models for the chemical kinetics and the vibrational non-equilibrium processes, it is new to compute such flow-fields with state-to-state models. This approach is very attractive because detailed models are efficient to model both the chemical reactions and the vibrational non-equilibrium at once, without making strong assumptions (like Boltzmann distribution) as it is the case with global models such as multi-temperature models for vibrational non-equilibrium modeling and global kinetics models for chemical reactions modeling.

For a realistic attempt in implementing a state-to-state model into a CFD code, a simple flow test-case and a simple detailed model are selected. The chosen flow test-case is a hypersonic nitrogen flow past a sphere flying at atmospheric entry conditions. Because of its high proportion in the Earth's atmosphere and its presence in the composition of the atmospheres of Mars and Titan, nitrogen is a good benchmark species for atmospheric entry studies. Many experiments (among them [24-26]) and models have been developed to understand the behavior of nitrogen in various configurations, making it the most referenced case. As for the selected state-to-state model, it is a state-specific vibrational model, that is a simplified version of CoRaM-N 2 , a collisional-radiative (CR) model recently developed for nitrogen [15, 18, 20]. The model CoRaM- $\mathrm{N}_{2}$ has already been implemented in a CFD code modeling 1D shock-induced plasmas using the Rankine-Hugoniot assumptions or quasi 1D recombining flows in diverging nozzles. It is the first time that this model is implemented in a full CFD code able to solve multidimensional flows. The selected CFD code to receive the state-to-state model for the present study is the PINENS code [27, 28]. This code is based on a shock-capturing method, without any assumption like the Rankine-Hugoniot assumption, and has the great advantage of being based on an implicit resolution of the aerothermodynamics equations, which allows to use large computational time steps and therefore to reduce the computational time to get the steady-state solution of the flow.

The objectives of the present paper are to show the feasibility of implementing a state-to-state model into a NavierStokes code, and of obtaining detailed gas composition and non-equilibrium state throughout the axi-symmetric flow past a blunt body with reasonable computational resources. The simplified version of CoRaM- $\mathrm{N}_{2}$ that is implemented in the Navier-Stokes code takes into account the species $\mathrm{N}_{2}$ and $\mathrm{N}$, and is vibrationnally specific for the $\mathrm{N}_{2}$ molecules on their ground electronic state. It allows to simulate the phase of ladder-climbing vibrational excitation and the resulting dissociation of $\mathrm{N}_{2}$. Another objective is to show how the global models perform compared to the detailed models, by comparing results obtained with the two approaches.

The outline of the paper is the following: First, the paper presents the vibrational-state specific model for nitrogen developed for the present study, as well as the conservation equations for a viscous flow in accordance with a state-to-state model. Then the global model and corresponding equations are briefly recalled so that the paper presents in parallel the two approaches: detailed and global. A short description of the aerothermodynamics numerical code PINENS in which the detailed and global models are implemented follows. The whole methodology is applied to the test-case of a nitrogen gas flowing around a sphere at Mach 32; this Mach number corresponds to one of the trajectory points of the Flight Investigation of Reentry Environment (FIRE) II probe [29]. Numerical results showing the population density fields of nitrogen on its various vibrational states throughout the shock layer are then presented and analyzed. Boltzmann diagrams of population distribution on the vibrational levels at various locations in the flow-field are presented. Finally, the flow-field results obtained with global models are compared to those obtained with the detailed model. 


\section{State-to-state modeling}

\section{A. Chemical species and vibrational energy states}

The vibrationally specific model subject of the present work is a simplified version of the collisional-radiative model CoRaM-N $\mathrm{N}_{2}$. It takes into account heavy, neutral particles only, as the PINENS code in which it is implemented is not yet able to take into account electronic non-equilibrium. That model considers each of the 68 vibrational states of $\mathrm{N}_{2}\left(0 \leq v \leq v_{\max }=67\right)$ on the ground electronic state - pointed out by Armenise et al. [26] - as well as the ground electronic state of N. In the following of the paper, the terms "species-states" or "pseudo-species" will refer to the chemical species $\mathrm{N}$ and $\mathrm{N}_{2}$ on their excited states, as displayed in Table 1 .

Table 1 Species and vibrational states considered in the vibrational-state specific model.

\begin{tabular}{ll}
\hline \hline Species & States \\
\hline $\mathrm{N}_{2}(v)$ & $v=0 \rightarrow v_{\max }=67$ for ground electronic state \\
$\mathrm{N}$ & ground electronic state \\
\hline \hline
\end{tabular}

\section{B. Collisional elementary processes}

According to the $\mathrm{CR}$ model CoRaM- $\mathrm{N}_{2}$ that is used as the basis to derive the present vibrational-state specific model, the vibrational excitation of molecules $\mathrm{N}_{2}$ takes place through vibration-vibration processes under molecular impact (VV-m processes), through vibration-translation processes under molecular impact (VT-m processes), or through vibration-translation processes under atomic impact (VT-a processes). The data used for the rate coefficients for these processes were calculated by Armenise et al. [5] and Esposito et al. [10]. Once vibrationnally excited, the molecules $\mathrm{N}_{2}$ may dissociate during collisions. For the dissociation of $\mathrm{N}_{2}$ through vibration-vibration processes under molecular impact (VV-m-D processes), through vibration-translation processes under molecular impact (VT-m-D processes), or through vibration-translation process under atomic impact (VT-a-D processes), the data of Armenise et al. and of Esposito et al. are also used. The resulting set of 6817 forward collisional elementary processes is listed in Table 2 . The backward collisional elementary processes are calculated from the forward rate coefficient and the corresponding equilibrium constant using the detailed balance principle. Thus, the set represents a total of about 13,600 forward and backward elementary processes between 69 "species-states".

Table 2 Elementary processes for the present vibrational-state specific model.

\begin{tabular}{lr}
\hline \hline Elementary processes & Process number \\
\hline vibration-vibration under molecular impact (VV-m) & 4489 \\
vibration-translation under molecular impact (VT-m) & 67 \\
vibration-translation under molecular impact leading to dissociation (VT-m-D) & 1 \\
vibration-vibration under molecular impact leading to dissociation (VV-m-D) & 67 \\
vibration-translation under atomic impact (VT-a) & 2125 \\
vibration-translation under atomic impact leading to dissociation (VT-a-D) & 68 \\
\hline \hline
\end{tabular}

\section{Mathematical formulation}

\section{Conservation equations}

The continuous, compressible, non-equilibrium, hypersonic gas flow past a space probe in atmospheric entry conditions is modeled with time-dependent conservation equations that include the mass conservation equations for 
every reacting chemical species on their various vibrational states, of momentum (Navier-Stokes equations), and of total energy. Because our goal is to predict the gas composition and its vibrational state throughout the flow-field with a vibrational-state specific model, the set of equations includes a mass conservation equation for each vibrational state of each chemical species. Each species $s$ on its excited state $v$-named "pseudo-species" or "species-state" and noted svhas a mass density $\rho_{s v}$ and the total mass density of the mixture is

$$
\rho=\sum_{s v=1}^{n_{s v}=69} \rho_{s v}
$$

The set of equations to be solved is then:

$$
\begin{aligned}
& \frac{\partial \rho_{s v}}{\partial t}+\nabla \cdot\left(\rho_{s v}\left(\mathbf{V}+\tilde{\mathbf{V}}_{s v}\right)\right)=\omega_{s v}^{C}, \quad s v=1, \ldots, n_{s v} \\
& \frac{\partial \rho \mathbf{V}}{\partial t}+\nabla \cdot(\rho \mathbf{V V}-\overline{\bar{\sigma}})=0 \\
& \frac{\partial \rho e}{\partial t}+\nabla \cdot(\rho e \mathbf{V}-\overline{\bar{\sigma}} \mathbf{V}+\mathbf{q})=0,
\end{aligned}
$$

where $\rho_{s v}$ is the density of "species-state" $s v, \rho \mathbf{V}$ the momentum, $\rho e$ the total energy, $\tilde{\mathbf{V}}_{s v}$ the diffusion velocity of "pseudo-species" sv in the gas mixture, $\overline{\bar{\sigma}}$ the stress tensor, $\mathbf{q}$ the convective heat flux, and $\omega_{s v}^{C}$ the chemical source term. In the mass conservation equation (2), the index $s v=1$ corresponds to $\mathrm{N}_{2}(\mathrm{v}=0), \ldots$, the index $s v=68$ to $\mathrm{N}_{2}(\mathrm{v}=67)$, and the index $s v=69$ to N. For a $2 \mathrm{D}$ or an axi-symmetric flow, the set of equations is then composed of 72 equations: 69 conservation equations for the "pseudo-species" $\mathrm{N}$ and $\mathrm{N}_{2}(\mathrm{v}),(\mathrm{v}=0,67)$, two equations for the conservation of the momentum, and one equation for the conservation of the total energy.

\section{Source terms}

Every chemical process $r=1, \ldots, n_{r}$ may be written in the following general form:

$$
\sum_{s v=1}^{n_{s v}} v_{s v, r}^{\prime} A_{s v} \underset{k_{r}^{b}}{\stackrel{k_{r}^{f}}{\rightleftharpoons}} \sum_{s v=1}^{n_{s v}} v_{s v, r}^{\prime \prime} A_{s v}, \quad r=1, \ldots, n_{r}
$$

where $A_{s v}$ is any of the "species-states" $s v, v_{s v, r}^{\prime}$ and $v_{s v, r}^{\prime \prime}$ the stoechiometric coefficients for the "species-state" sv in process $r$, and $k_{r}^{f}$ and $k_{r}^{b}$ the forward and backward rates for the process $r$. In order to make the rate coefficients easily readable by PINENS code, every rate is expressed under the modified Arrhenius form

$$
\begin{aligned}
& k_{r}^{f}(T)=C_{r}^{f} T^{\eta_{r}^{f}} \exp \left(-\frac{\theta_{r}^{f}}{T}\right) \\
& k_{r}^{b}(T)=C_{r}^{b} T^{\eta_{r}^{b}} \exp \left(-\frac{\theta_{r}^{b}}{T}\right) .
\end{aligned}
$$

The data for $C_{r}^{f}, C_{r}^{f}, \eta_{r}^{f}, \eta_{r}^{b}, \theta_{r}^{f}$ and $\theta_{r}^{b}$ are calculated from CoRaM-N 2 initial data.

The detailed species-states source term for equation (2) is then expressed as:

$$
\omega_{s v}^{C}=M_{s v} \sum_{r=1}^{n_{r}}\left(v_{s v, r}^{\prime}-v_{s v, r}^{\prime \prime}\right)\left[-k_{r}^{f} \prod_{j=1}^{n_{s v}}\left(\frac{\rho_{j}}{M_{j}}\right)^{v_{s v, r}^{\prime}}+k_{r}^{b} \prod_{j=1}^{n_{s v}}\left(\frac{\rho_{j}}{M_{j}}\right)^{v_{s v, r}^{\prime \prime}}\right], \quad s v=1, \ldots, n_{s v}
$$

where $M_{s v}$ is the molar mass of species $s$ on vibrational state $v$.

\section{Global modeling}

In order to make an easy comparison between the global models usually used in numerical experiments of atmospheric entries and the state-to-state model used in the present study, the well-known global models and corresponding equations are recalled here-after: 


\section{A. Chemical species and vibrational energies}

When modeling a chemically and vibrationally non-equilibrium nitrogen flow with global models, the chemical species and vibrational energies listed in Table 3 are considered, and the global chemical kinetics model for a mixture composed of the two species $\mathrm{N}_{2}$ and $\mathrm{N}$ is a set of two dissociation-recombination reactions, as shown in Table 4

\section{Table 3 Species and vibrational energy.}

\begin{tabular}{ll}
\hline \hline Species & Vibrational energy \\
\hline $\mathrm{N}_{2}$ & $e_{N_{2}}^{V}$ \\
$\mathrm{~N}$ & - \\
\hline \hline
\end{tabular}

Table 4 Global chemical kinetics model.

\begin{tabular}{lll}
\hline $\mathrm{N}_{2}+\mathrm{N}_{2}$ & $\rightleftharpoons \mathrm{N}+\mathrm{N}+\mathrm{N}_{2}$ \\
$\mathrm{~N}_{2}+\mathrm{N}$ & $\rightleftharpoons \mathrm{N}+\mathrm{N}+\mathrm{N}$ \\
\hline
\end{tabular}

\section{B. Conservation equations}

When modeling a reactive gas with a global model for the chemical kinetics, a mass conservation equation is written and solved for each chemical species $s$ :

$$
\frac{\partial \rho_{s}}{\partial t}+\nabla \cdot\left(\rho_{s}\left(\mathbf{V}+\tilde{\mathbf{V}}_{s}\right)\right)=\omega_{s}^{C}, \quad s=1, \ldots, n_{s} .
$$

When modeling a gas in thermal non-equilibrium state with a multi-temperature model for the vibrational relaxation, a conservation equation for each form of energy that is treated separately - the vibrational energy, $\rho_{v} e_{v}^{V}$, in the present study - is written and solved for each vibrating molecule $v$ :

$$
\frac{\partial \rho_{v} e_{v}^{V}}{\partial t}+\nabla \cdot\left(\rho_{v} e_{v}^{V}\left(\mathbf{V}+\tilde{\mathbf{V}}_{v}\right)+\mathbf{q}_{v}^{V}\right)=\omega_{v}^{V}, \quad v=1, \ldots, n_{v}
$$

where the vibrational energy source term $\omega_{v}^{V}$ is expressed according to Landau-Teller formulation [30], and the characteristic time of vibrational relaxation from Millikan and White [31].

\section{Source terms for chemical species mass conservation}

The expression to compute the source terms for the mass conservation equations for the global models is the same as the expression to compute the source terms for the mass conservation equations for the detailed model, provided the subscripts $s v$ - corresponding to a "pseudo-species" - be replaced with the subscript $s$-corresponding to a whole chemical species. The source term is then written as:

$$
\omega_{s}^{C}=M_{s} \sum_{r=1}^{n_{r}}\left(v_{s, r}^{\prime}-v_{s, r}^{\prime \prime}\right)\left[-k_{r}^{f} \prod_{j=1}^{n_{s}}\left(\frac{\rho_{j}}{M_{j}}\right)^{v_{s, r}^{\prime}}+k_{r}^{b} \prod_{j=1}^{n_{s}}\left(\frac{\rho_{j}}{M_{j}}\right)^{v_{s, r}^{\prime \prime}}\right], \quad s=1, \ldots, n_{s}
$$

where $M_{s}$ is the molar mass of the chemical species $s$. Several data for the kinetics rates are available in the literature, among them those from Dunn-Kang [32], from Park [22], and from Gupta et al. [33]. 


\section{PINENS code description}

The code used to solve either set of equations presented in sections III]and[IV]is the Parallel Implicit Non-Equilibrium Navier-Stokes (PINENS) code. It is designed to simulate the chemical and thermal non-equilibrium processes in shock layers surrounding a space vehicle entering any type of atmosphere, and has been used in various flow configurations [27, 28, 34]. It is based on a finite-volume formulation of the set of equations on structured grids. The convective fluxes at the interfaces of each cell are evaluated with the approximate Riemann solver of Roe, and the dissipative fluxes are expressed with a classical finite-difference formulation. To ensure high-accuracy of the convective flux evaluation, the conservative variables are reconstructed at the cell interfaces by means of second-order accurate total-variation-diminishing schemes. To prevent oscillations in the second-order reconstruction schemes, the slopes are limited with the vanLeer slope limiter. To avoid the carbuncle problem - if this is necessary - the entropy fix $\mathrm{H}$-correction [27] is used. The H-correction entropy fix has the useful feature of automatically adding extra numerical dissipation where needed only, and not elsewhere. The time integration is either first or second order accurate, and is fully implicit for robustness and speed of convergence reasons. The implicit resolution is done by the data parallel line relaxation (DPLR) method [35]. Depending on the grid features and on the flow characteristics, the CFL number can be quite large (100 and above) leading to a fast convergence of the computations of the flow field. The implicit time integration is a very useful feature of PINENS, especially when treating large problems like in the present work. It allows to obtain the steady-state solution of the flow field in a reasonable computational time. It is that particular feature that allows us to perform the simulations of the aerothermodynamics fields for atmospheric entries with a state-to-state model. Finally, PINENS is a fully parallel code based on automatic domain decomposition, where the communications between the computational domains are done with the library MPI.

\section{Application to hypersonic flows}

If the reactions between chemical species excited on their vibrational states modeled with the detailed collisionalradiative models CoRaM- $\mathrm{N}_{2}$ [20], and the spatial evolution of these pseudo-species behind a normal shock wave resolved with a one-dimension Rankine-Hugoniot solver, have already been simulated, it is new to do such a work for a two-dimension or axi-symmetric flow resolved with a shock-capturing method implemented in a CFD code.

\section{A. Mach number $\mathcal{M}_{0} \sim 32$ flight conditions}

To model and analyze the gas in thermal and chemical non-equilibrium state in an axi-symmetric shock layer, by means of the models presented in the previous sections, the axi-symmetric flow past a sphere of a 1-meter radius entering a nitrogen atmosphere (initially at the vibrational level $v=0$ ) at a speed of approximately Mach 32 is selected. The simulations are done on the fore-body part of the sphere, where the shock layer develops and where the gas goes through various aero-thermodynamical states. The flight conditions of this numerical experiment corresponds to the Fire II flight experiment near the peak heating undergone by the thermal protection. The corresponding upstream conditions, as well as the atmosphere composition, and chemical kinetics models are given in Table 5.

Table 5 Flight conditions for the sphere, and gas composition.

\begin{tabular}{ll}
\hline \hline Velocity & $10600 \mathrm{~m} / \mathrm{s}$ \\
\hline Temperature & $274 \mathrm{~K}$ \\
\hline Pressure & $54 \mathrm{~Pa}$ \\
\hline Atmosphere & $100 \% \mathrm{~N}_{2}(\mathrm{v}=0)$ \\
\hline Chemical kinetics & 69 pseudo-species : $\mathrm{N}_{2}(\mathrm{v}=0,67), \mathrm{N}$ \\
\hline Wall Temperature & $1500 \mathrm{~K}$ \\
\hline \hline
\end{tabular}

\section{B. Grid convergence study}

A particular attention has been given in this study to perform the numerical experiments on a grid that corresponds to the grid convergence of the results, while still keeping the computational time as short as possible. To respect these 
two constraints the grid was refined in the normal direction to the sphere, that is in the main direction of the flow through the shock and across the boundary layer, and released in the direction longitudinal to the sphere.

\section{Results}

For an atmosphere initially composed of $100 \%$ of $\mathrm{N}_{2}$ on $\mathrm{v}=0$ vibrational level and according to the considered vibrational state-to-state model [20], the molecules $\mathrm{N}_{2}$ on their zero-vibrational level collide, get excited, and - depending on the type of collisions - get dissociated across the shock wave. These collisional processes lead to a gas mixture composed of the two species $\mathrm{N}_{2}$ and $\mathrm{N}, \mathrm{N}_{2}$ being on various vibrational states depending on the excitation processes considered, on the temperature and on other flow conditions within the shock layer.

Flow-field solutions (temperature $T$ and mass fractions of $\mathrm{N}_{2}$ molecule on their various vibrational states) around the sphere obtained with the physical models described in this paper are presented in the next sections.

\section{A. Step-by-step introduction of detailed-reaction groups}

The vibrational-state specific model implemented in PINENS code is split into several groups of reactions; each group is implemented one after the other in order to show the specific effect of each process group on the flow field variables (temperature, shock position) and on the population densities of the 68 vibrational levels of $\mathrm{N}_{2}$ and of the atomic species $\mathrm{N}$, in the shock layer. The step-by-step implementation of the process groups is summarized in Table 6 .

Table 6 Step-by-step implementation of the vibrational-state specific process groups.

\begin{tabular}{lr}
\hline \hline Process groups & Total processes number \\
\hline VV-m (4489) & 4489 \\
\hline VT-m (67) & 67 \\
VT-m (67) + VT-m-D (1) & 68 \\
VT-m (67) + VV-m-D (67) & 134 \\
VT-m (67) + VT-m-D (1) + VV-m-D (67) & 135 \\
VT-m (67) + VT-m-D (1) + VV-m-D (67) + VT-a (2125) & 2260 \\
VT-m (67) + VT-m-D (1) + VV-m-D (67) + VT-a (2125) + VT-a-D (68) & 2328 \\
\hline \hline
\end{tabular}

\section{B. Presentation and analysis of the results}

\section{VV-m: 4489 processes}

The first step in analyzing the effect of each group of processes on the flow field (temperature, species densities, ...) consists in considering the processes for VV exchanges by molecular impact (VV-m). Surprisingly, introducing the reactions corresponding to these processes does not produce any visible effect on the temperature nor on the species profiles in the shock layer. Figure 1 shows that the shock position, the temperature, and the total density evolutions throughout the shock layer are the same when VV-m processes are taken into account (solid lines) as when no processes are taken into account (dashed lines). The population densities of $\mathrm{N}_{2}$ vibrational levels are identical to their initial value set to $10^{-17}$, except the populations of levels $v=1$ to $v=4$ that increase of 3 orders of magnitude in the shock front and then decrease to return to their initial values, which is insignificant. Other simulations with taking into account the VV exchanges by molecular impact (VV-m) together with the VT exchanges by molecular impact (VT-m) showed that the VV-m processes do not generate any visible effect on the population densities of the vibrational levels. This shows that the VV-m processes are not efficient in the present flow test-case. Therefore, the rest of the computations are done without the 4489 processes for VV exchanges by molecular impact (VV-m). 


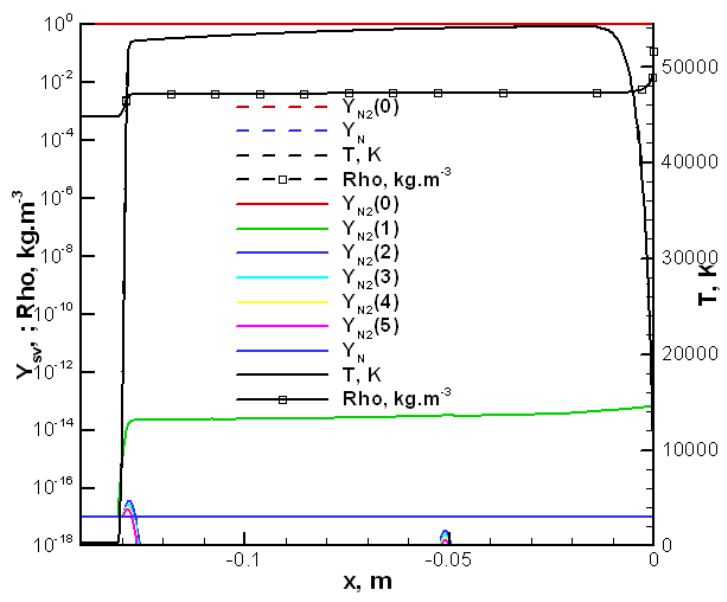

Fig. 1 Temperature and mass fractions of $\mathrm{N}_{2}(\mathrm{v}=\mathbf{0 , 6 7})$ along the stagnation line of the flow in the shock layer around the sphere. Comparison between no chemical processes (dashed lines) and $4489 \mathrm{VV}$-m processes (solid lines). No effect of the VV excitation.

\section{VT-m: 67 processes}

The second step in analyzing the effect of a process group on the flow field and on the vibrational level population densities consists in taking into account the VT exchanges by molecular impact (VT-m). The results then obtained are shown in Figs. 2 and 3

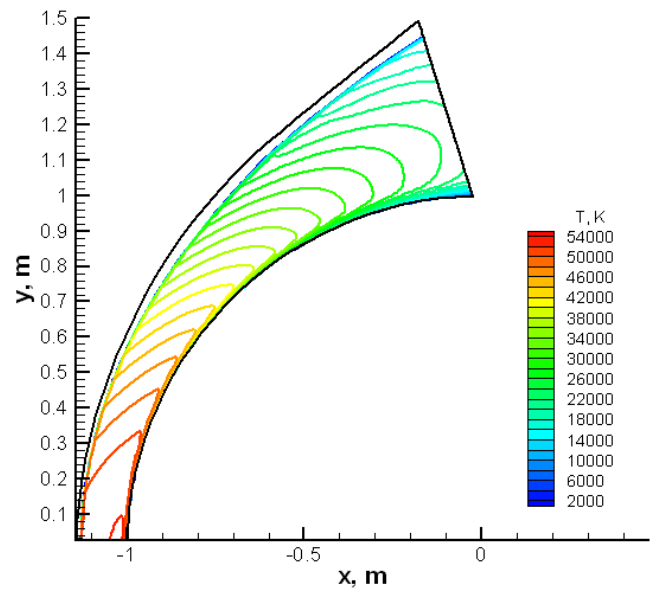

Fig. 2 Temperature contours. Effect of the VT excitation by molecular impact (processes 1 to 67 are included in the computations).

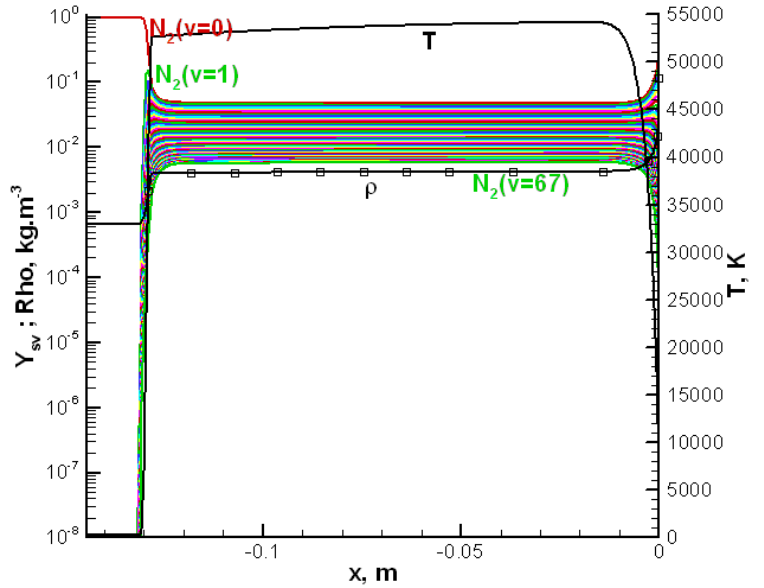

Fig. 3 Temperature and mass fractions of $\mathbf{N}_{2}(\mathbf{v}=0,67)$. Effect of the VT excitation by molecular impact (processes 1 to 67 are included in the computations).

Interestingly, the temperature contours in Fig. 2 and temperature profiles along the stagnation line in Fig. 3 , are similar to those obtained when no chemical reactions are taken into account in the gas flow: the temperature is maximum in the entire shock layer, with a maximum reached near the stagnation area of the flow, right in front of the boundary 
layer. This means that the VT-m processes do not take much thermal energy from the gas. The evolutions of the mass fractions of each vibrational level of $\mathrm{N}_{2}$ (from $\mathrm{v}=0$ to 67 ) along the stagnation line throughout the shock layer, including the boundary layer, are also shown in Fig. 3. It has to be noted here that the increase of the population mass fraction slightly in front of the temperature increase is simply due to the logarithm scale for the population mass fractions while the temperature is plotted according to a linear scale. The fundamental vibrational level of $\mathrm{N}_{2}$ is depopulated across the shock wave to the profit of the excited states $v=1$ to 67 . As expected, the lowest levels are the most populated levels. The behavior of the first 10 vibrational levels right behind the shock wave is interesting: their population increases in the shock wave, then decreases only $1 \mathrm{~mm}$ behind the shock front, to the profit of the excitation of higher vibrational states. In the boundary layer, the wall temperature being fixed to $1500 \mathrm{~K}$, the gas temperature decreases strongly, which leads to the depopulation of the high vibrational levels and the repopulation of the lower levels, as this could be expected.

\section{VT-m+VT-m-D: 68 processes}

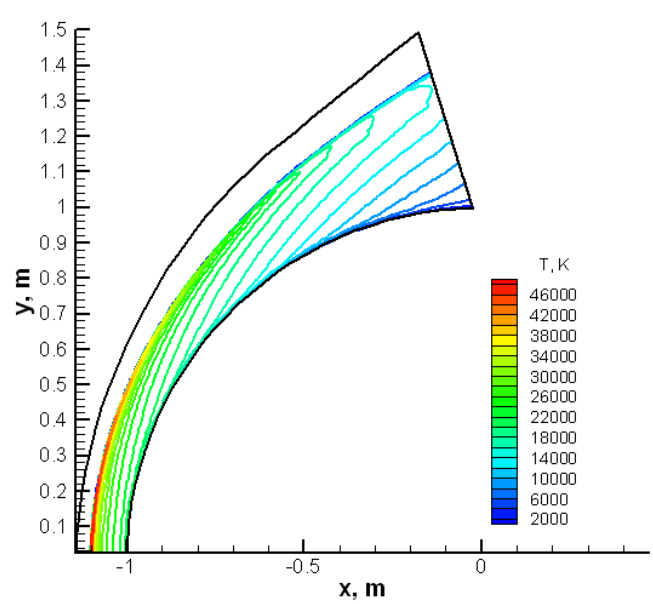

Fig. 4 Temperature contours. Effect of the VT excitation by molecular impact and VT excitation leading to dissociation (processes 1 to 68 are included in the computations).

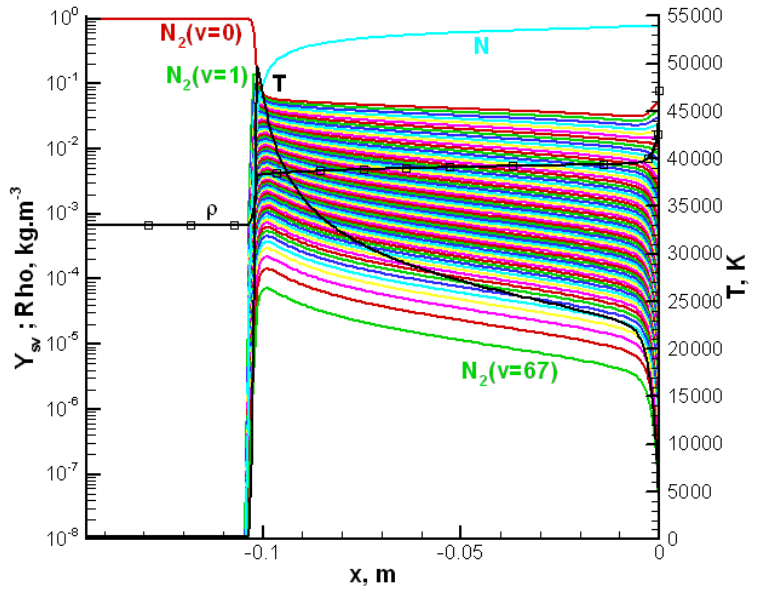

Fig. 5 Temperature and mass fractions of $\mathrm{N}_{2}(\mathrm{v}=0,67)$ and $\mathrm{N}$ along the stagnation line. Effect of the VT excitation by molecular impact and VT excitation leading to dissociation (processes 1 to 68 are included in the computations).

The addition of the VT process by molecular impact leading to the dissociation (VT-m-D) tends to reduce the shock layer width from approximately $13 \mathrm{~cm}$ to $11 \mathrm{~cm}$ (see Figs. 4 and 5, in comparison with Figs. 2 and 33. The introduction of this single process of dissociation into the computations also changes the temperature profile across the shock layer: the temperature is no longer maximum at 53,000 K throughout the shock layer but peaks at 46,000 K right behind the shock front then decreases (Fig. 55). This new temperature profile is similar to the temperature profiles usually observed when chemical reactions are taken into account through global models, and is typical of shock layer where dissociation processes take place. Regarding the species profiles within the shock layer, the atomic nitrogen is now the major species present in the shock layer. All the vibrational levels of $\mathrm{N}_{2}$ are less populated, especially the highest levels - because of the dissociation of $\mathrm{N}_{2}$ from the highest vibrational levels - to the profit of the atomic species. This means that the VT-exchange by molecular impact leading to dissociation (process VT-m-D) is a very efficient process among the many reactions of the vibrationally specific model implemented in the CFD code. This reaction of dissociation of $\mathrm{N}_{2}(\mathrm{v})$ also absorbs a large amount of thermal energy. For example, the temperature that was approximately equal to $53000 \mathrm{~K}$ in the shock layer $2 \mathrm{~mm}$ from the stagnation point (see Fig. 3) is now equal to $22000 \mathrm{~K}$ at the same location. Moreover, while the densities of each vibrational level were constant throughout the shock layer when only VT-m processes were taken into account, those densities are now slightly decreasing along the stagnation line of the flow field while the density of $\mathrm{N}$ is increasing. This means that the dissociation process takes place not only right behind the shock wave, but throughout the shock layer. 


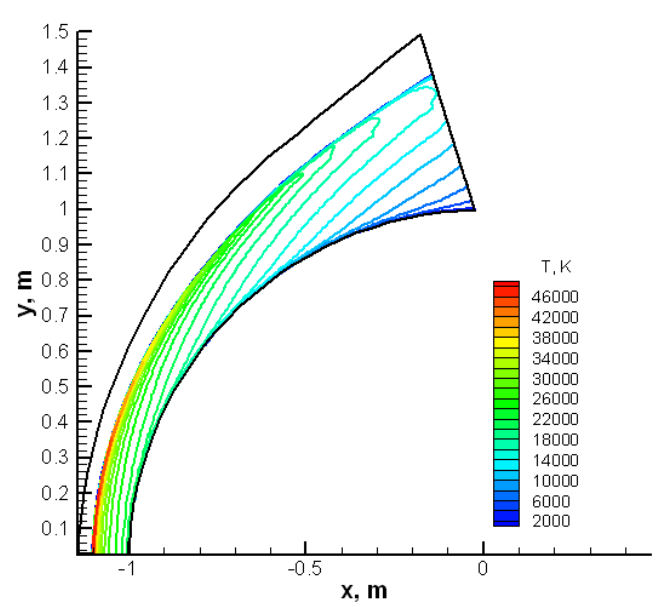

Fig. 6 Temperature contours. Effect of the VT excitation by molecular impact and VV excitation leading to dissociation (processes 1 to 134 are included in the computations).

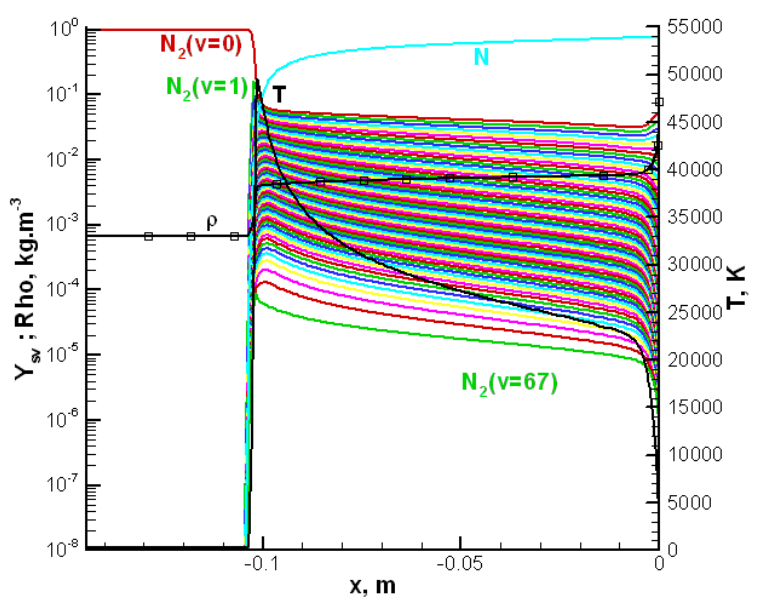

Fig. 7 Temperature and mass fractions of $\mathrm{N}_{2}(\mathrm{v}=\mathbf{0 , 6 7})$ and $\mathrm{N}$ along the stagnation line. Effect of the VT excitation by molecular impact and VV excitation leading to dissociation (processes 1 to 134 are included in the computations).

If, instead of adding the process VT-m-D to the processes VT-m, one adds the 67 processes VV-m-D, the results are the same as those obtained when only the processes VT-m are taken into account, showing the the VV-m-D are not efficient in the present test-case, as this is shown by comparing Fig. 6 to Fig. 4 and Fig. 7 to Fig. 5

\section{VT-m $+V T-m-D+V V-m-D: 135$ processes}

In the same way, when the processes VT-m + VT-m-D + VV-m-D are taken into account in the simulations (figures not shown), the results are the same as when only the processes VT-m + VT-m-D are taken into account. These observations let us say that the 67 processes VV-m-D have no visible effect on the population densities of the vibrational levels of $\mathrm{N}_{2}$ nor on the flow characteristics (temperature, shock position,...). It seems then that the VV processes (leading to dissociation or not) are not efficient in the present test-case.

\section{6. $V T-m+V T-m-D+V V-m-D+V T-a: 2260$ processes}

The introduction of the 2126 VT processes by atomic impact (VT-a) has a large effect on the flow field (Figs. 8 and 9): these reactions, like the process VT-m-D, lead to decreasing the shock layer width (from $11 \mathrm{~cm}$ to $8.5 \mathrm{~cm}$ approximately) and the temperature peak (from 46,000 K down to 38,000 K). Regarding the population densities in the shock layer, it is clear that the highest vibrational levels of $\mathrm{N}_{2}$ are even more depopulated to the profit of atomic nitrogen production than they were in the previous case. Again, the densities of each vibrational level in the shock layer decreases along the stagnation line even more than in Fig. 5. meaning that the VT processes by atomic impact (VT-a) are effective throughout the shock layer and not only right behind the shock wave.

The curve of $\mathrm{N}$ population density (Fig. 9) shows that there is more $\mathrm{N}$ in the shock layer when VT-a processes are taken into account, while there is no additional reaction of dissociation (only the VT-m-D reaction that was included previously). The VT-a processes depopulate the highest vibrational levels, which means that they transfer energy from the vibrational modes to the translational mode. This energy transfer makes the temperature increase temporarily, which in turn makes the VT-m-D process more active to dissociate more $\mathrm{N}_{2}$ molecules and produce more $\mathrm{N}$ atoms.

In the boundary layer, the species densities profiles (Fig. 9 like in Fig. 5) have the same behavior: because of the flow temperature profile to reach the wall temperature of $1500 \mathrm{~K}$, the lowest vibrational energy levels $(\mathrm{v}=1$ to 5) are slightly repopulated, while all the other levels are depopulated. 


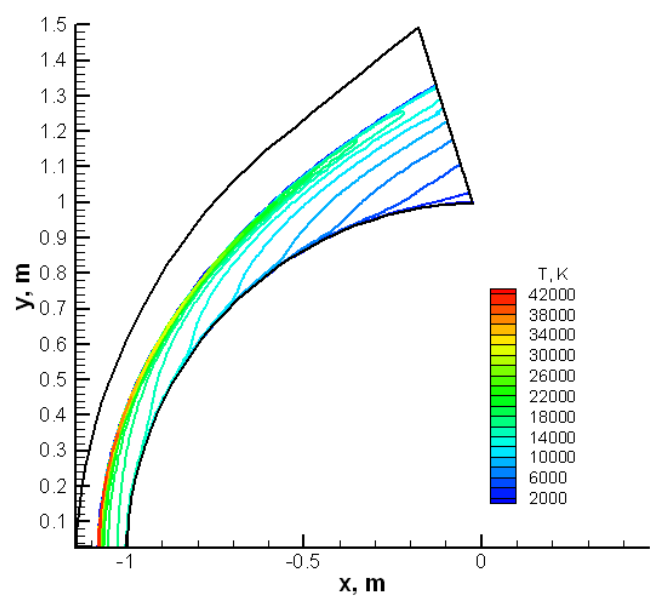

Fig. 8 Temperature contours. Effect of the VT excitation by molecular and atomic impacts, and of the VT and VV excitations by molecular impact leading to dissociation (processes 1 to 2260 are included in the computations).

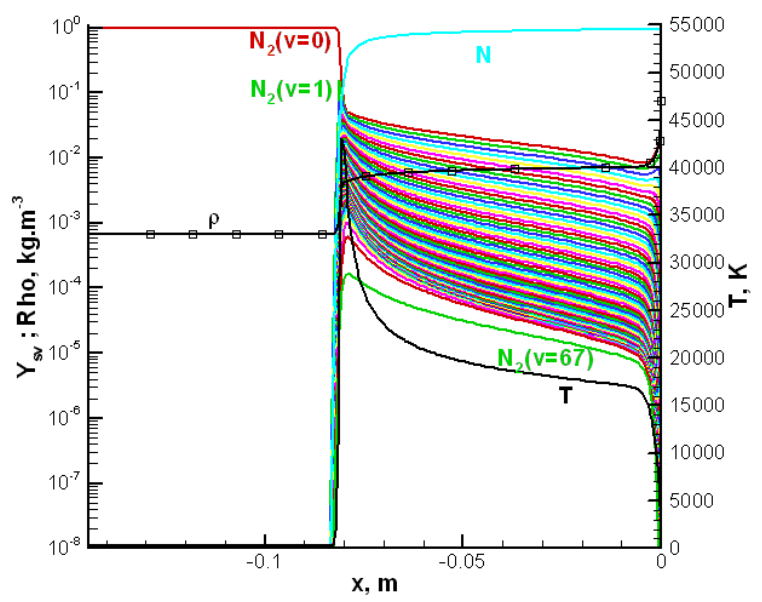

Fig. 9 Temperature and mass fractions of $N_{2}(v=0,67)$ and $\mathbf{N}$ along the stagnation line. Effect of the VT excitation by molecular and atomic impacts, and of the VT and VV excitations by molecular impact leading to dissociation (processes 1 to 2260 are included in the computations).

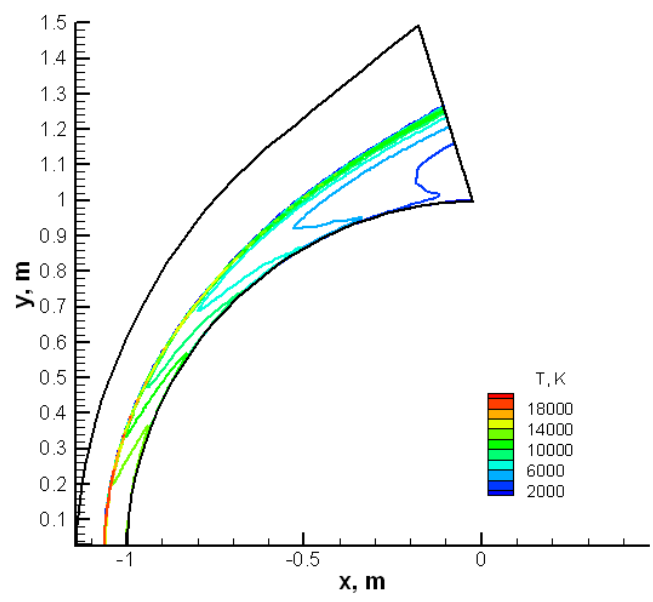

Fig. 10 Temperature contours. Effect of the VT excitation by molecular and atomic impacts, of the VT excitations by molecular and atomic impacts leading to dissociation, and of the VV excitations by molecular impact leading to dissociation (processes 1 to 2328 are included in the computations).

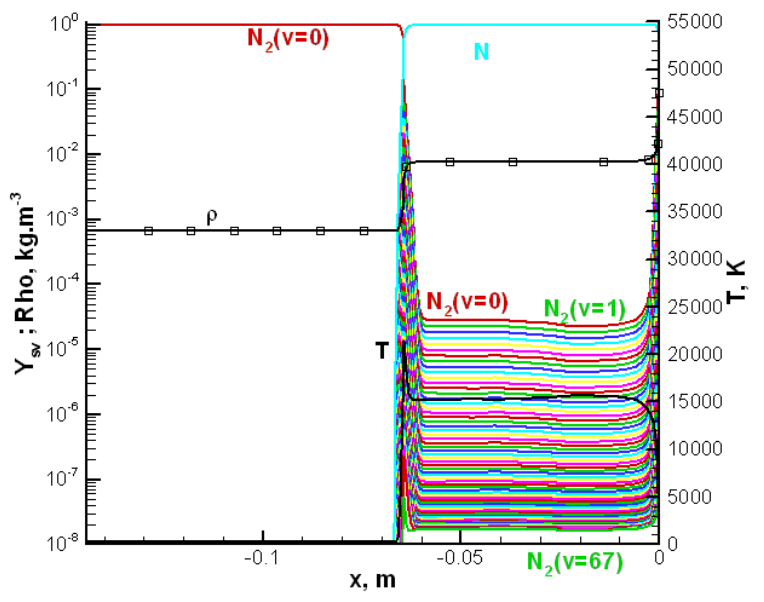

Fig. 11 Temperature and mass fractions of $N_{2}(v=0,67)$ and $N$ along the stagnation line. Effect of the VT excitation by molecular and atomic impacts, of the VT excitations by molecular and atomic impacts leading to dissociation, and of the $\mathrm{VV}$ excitations by molecular impact leading to dissociation (processes 1 to 2328 are included in the computations).

Adding the 68 reactions corresponding to the VT processes by atomic impact leading to dissociation (VT-a-D) that is the last group of processes of the present detailed model - results in a complete dissociation of $\mathrm{N}_{2}(\mathrm{v})$. Like 
in the previous steps, the flow field is strongly affected by the introduction of these additional reactions: again, the shock standoff distance is decreased (from $8.5 \mathrm{~cm}$ to $7 \mathrm{~cm}$ ) and the temperature peak is decreased from $38,000 \mathrm{~K}$ to 18,000 K (Figs. 10 and 11). Regarding the species densities, if the curves show that the various vibrational levels are all populated through the shock wave, they are depopulated right behind the shock wave. This means that the additional reactions corresponding to the VT processes by atomic impact leading to dissociation (VT-a-D) are very efficient and finish transferring vibrational energy of $\mathrm{N}_{2}(\mathrm{v})$ to translational energy in order to dissociate the molecules, whatever their vibrational level. Interestingly, the temperature profile along the stagnation line slightly increases until the boundary layer where the temperature drops to reach to wall temperature. In the boundary layer, the vibrational levels get repopulated because of the temperature drop.

\section{Boltzmann distribution - Where is the vibrational equilibrium reached in the shock layer ?}

In order to see if the distribution of the populations on the vibrational levels follows a Boltzmann distribution, Boltzmann diagrams of the $\mathrm{N}_{2}(\mathrm{v})$ densities on the vibrational levels at different positions (marked A to L) across the boundary layer are presented in Figs 12 to 15 , for each step to include the successive groups of processes. The Boltzmann distribution is reached when the curves representing the level populations (or mass fractions) - expressed in a logarithmic scale - versus the energies of the levels - expressed in a linear scale - are linear.

In the Boltzmann diagrams, letters A to L represent the positions along the stagnation line from the stagnation point backward to the shock front according to Table 7

Table 7 Positions along the stagnation line upstream of the boundary layer.

\begin{tabular}{ll}
\hline \hline curve & $x, \mathrm{~mm}$ \\
\hline $\mathrm{A}$ & 0 (stagnation point) \\
$\mathrm{B}$ & $-7.35 \cdot 10^{-2}$ \\
$\mathrm{C}$ & $-1.67 \cdot 10^{-1}$ \\
$\mathrm{D}$ & $-3.04 \cdot 10^{-1}$ \\
$\mathrm{E}$ & $-5.05 \cdot 10^{-1}$ \\
$\mathrm{~F}$ & $-8.74 \cdot 10^{-1}$ \\
$\mathrm{G}$ & $-1.34 \cdot 10^{0}$ \\
$\mathrm{H}$ & $-2.03 \cdot 10^{0}$ \\
$\mathrm{I}$ & $-3.05 \cdot 10^{0}$ \\
$\mathrm{~J}$ & $-4.53 \cdot 10^{0}$ \\
$\mathrm{~K}$ & $-6.72 \cdot 10^{0}$ \\
$\mathrm{~L}$ & $-9.93 \cdot 10^{0}$ \\
\hline \hline
\end{tabular}

In Figs. 13 and 14 the Boltzmann diagrams show that the Boltzmann distribution is not reached for the cases (VT-m) + VT-m-D), $(V T-m)+(V V-m-D)$. For the case $(V T-m)+(V T-m-D)+(V V-m-D)$, the Boltzmann diagram (not shown) is very similar to the one for the case $(\mathrm{VT}-\mathrm{m})+\mathrm{VT}-\mathrm{m}-\mathrm{D})$. On the other hand, the Boltzmann distribution is reached 0.5 $\mathrm{mm}$ in front of the stagnation point for the case (VT-m) (Fig. 12) and $2 \mathrm{~mm}$ in front of the stagnation point for the case $(\mathrm{VT}-\mathrm{m})+(\mathrm{VT}-\mathrm{m}-\mathrm{D})+(\mathrm{VV}-\mathrm{m}-\mathrm{D})+(\mathrm{VT}-\mathrm{a})$ (not shown). A summary of if and where the Boltzmann distribution is reached is given in Table 8

These results show that the Boltzmann distribution assumption usually done in the computations with multitemperature models for simulating the vibrational relaxation through a shock wave or across a boundary layer is not valid in the boundary layer.

\section{Comparison of detailed and global kinetics rate models}

Global models for kinetics rates are widely used in the literature to compute hypersonic, reacting gas flows in reentry conditions. Since we are now able to compute flow fields in reentry conditions with detailed models for kinetics rates, it is interesting to compare results obtained with the two approaches. A comparison of the $\mathrm{N}$ density and of the $\mathrm{N}_{2}$ density 


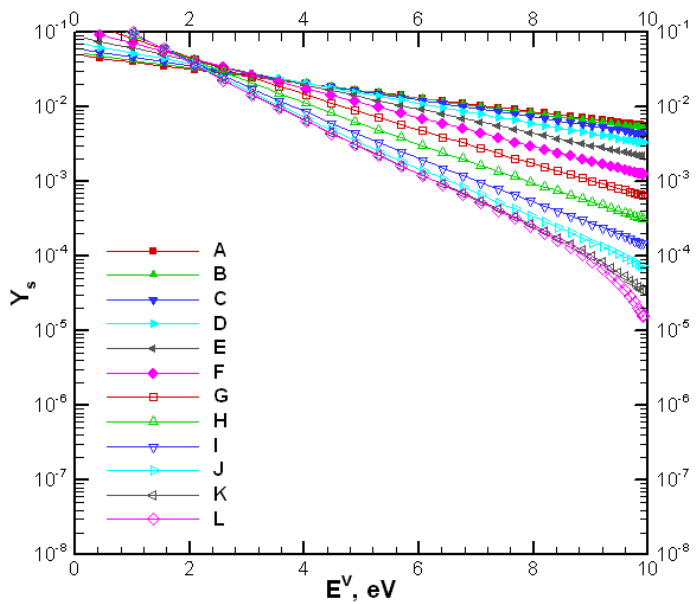

Fig. 12 Boltzmann diagram across the boundary layer. (processes (VT-m) are included in the computations).

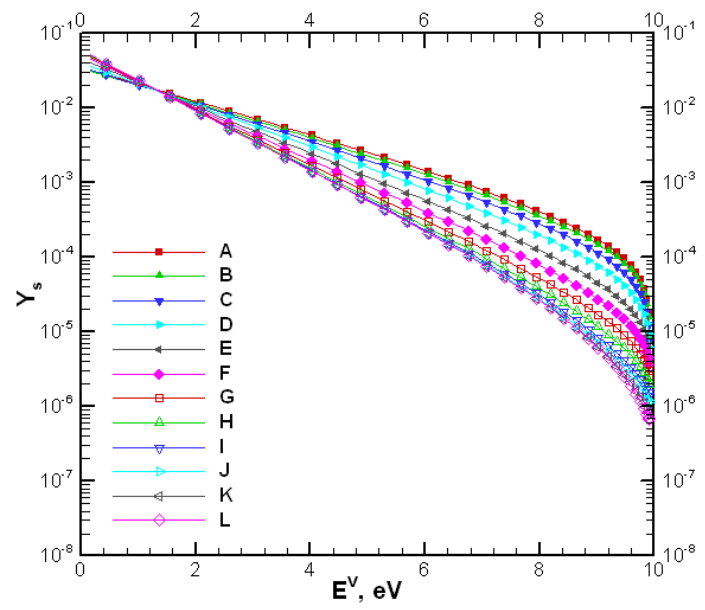

Fig. 14 Boltzmann diagram across the boundary layer. (processes $(\mathrm{VT}-\mathrm{m})+(\mathrm{VV}-\mathrm{m}-\mathrm{D})$ are included in the computations).

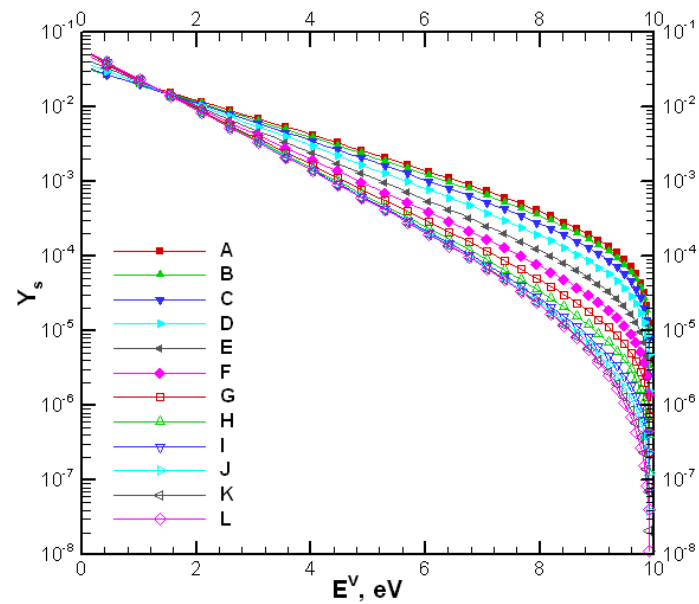

Fig. 13 Boltzmann diagram across the boundary layer. (processes (VT-m) + (VT-m-D) are included in the computations).

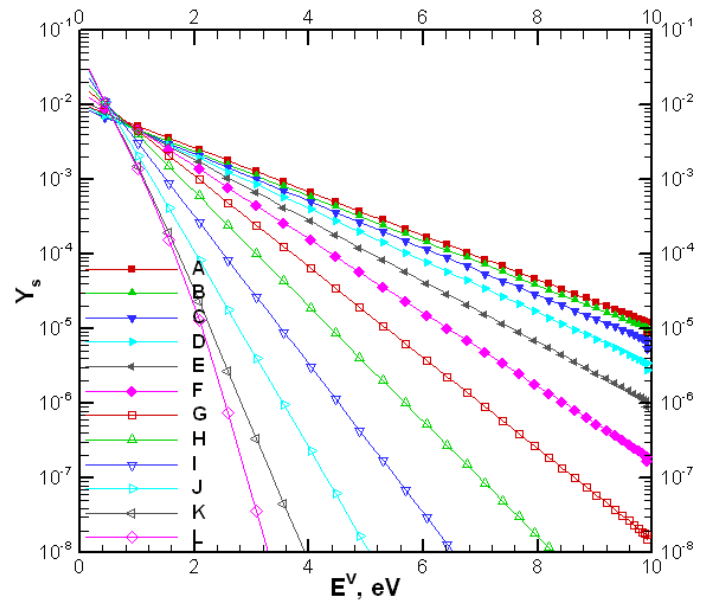

Fig. 15 Boltzmann diagram across the boundary layer. (processes $($ VT-m) + (VT-m-D) + (VV-m-D) + (VT-a) are included in the computations).

(summed-up over the vibrational levels for the vibrational specific model case), along the stagnation line of the shock layer flow around the sphere, and obtained with the two approaches is shown in Fig. 16. Several global models are compared: Dunn-Kang [32], Park [22], Gupta et al. [33] and CORIA. The global model from CORIA results from reducing the vibrational specific model. Differences on the mass fractions and on the temperature are visible near the shock wave, and in the boundary layer. A close-up view of the boundary layer in Fig. 17 shows how the global models differ and how the CORIA detailed and global models agree. The global model (solid lines) reproduces perfectly the results obtained with the vibrational specific model (dots). This agreement validates the methodology for implementing the detailed model in PINENS code. 
Table 8 Distance $x$ in front of the stagnation point (sphere surface) to obtain a Boltzmann distribution. '-' indicates that the Boltzmann distribution is not reached.

\begin{tabular}{lr}
\hline \hline processes & $x, \mathrm{~mm}$ \\
\hline (VT-m) & -0.5 \\
$(\mathrm{VT}-\mathrm{m})+(\mathrm{VT}-\mathrm{m}-\mathrm{D})$ & - \\
$(\mathrm{VT}-\mathrm{m})+(\mathrm{VV}-\mathrm{m}-\mathrm{D})$ & - \\
$(\mathrm{VT}-\mathrm{m})+(\mathrm{VT}-\mathrm{m}-\mathrm{D})+(\mathrm{VV}-\mathrm{m}-\mathrm{D})$ & - \\
$(\mathrm{VT}-\mathrm{m})+(\mathrm{VT}-\mathrm{m}-\mathrm{D})+(\mathrm{VV}-\mathrm{m}-\mathrm{D})+(\mathrm{VT}-\mathrm{a})$ & -2.0 \\
$(\mathrm{VT}-\mathrm{m})+(\mathrm{VT}-\mathrm{m}-\mathrm{D})+(\mathrm{VV}-\mathrm{m}-\mathrm{D})+(\mathrm{VT}-\mathrm{a})+(\mathrm{VT}-\mathrm{a}-\mathrm{D})$ & -0.2 \\
\hline \hline
\end{tabular}

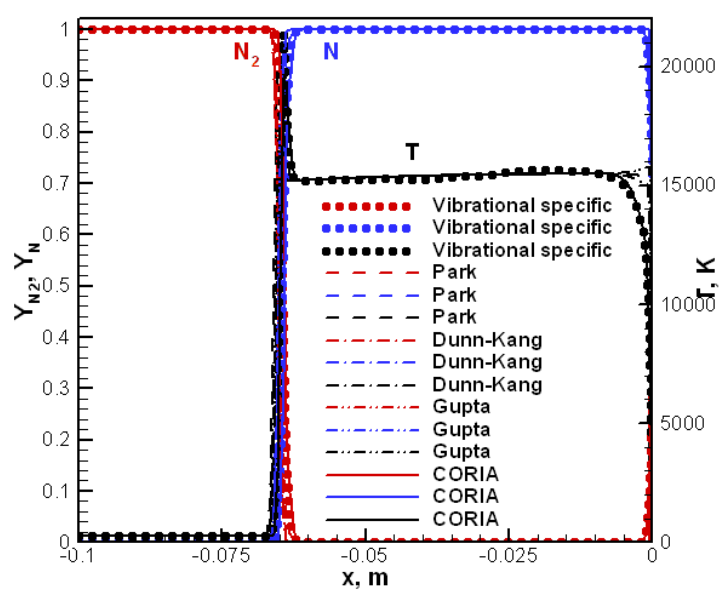

Fig. 16 Temperature and mass fractions of $\mathbf{N}_{2}$ and $\mathrm{N}$ along the stagnation line. Comparison of various global models (Park, Dunn-Kang, Gupta et al., CORIA) and vibrational specific model.

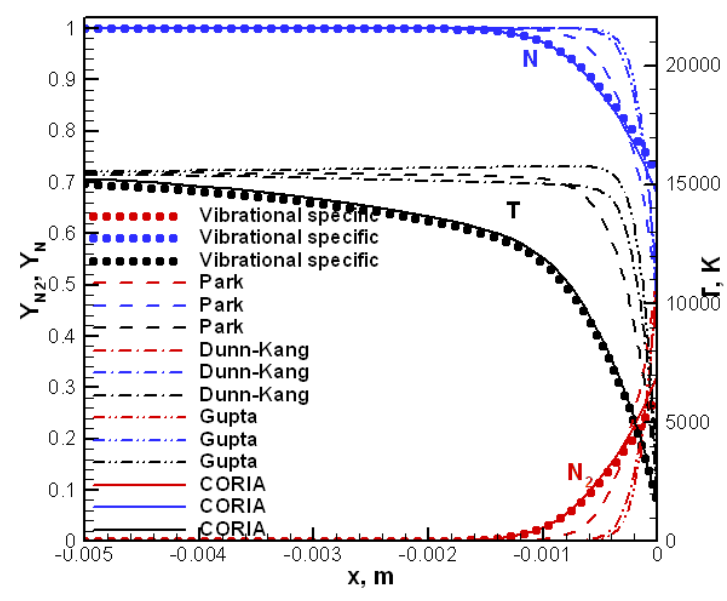

Fig. 17 Temperature and mass fractions of $\mathbf{N}_{2}$ and $\mathbf{N}$ along the stagnation line. Comparison of various global models (Park, Dunn-Kang, Gupta et al., CORIA) and vibrational specific model. Close-up view near the boundary layer.

\section{Conclusions}

In this paper, a vibrational-state specific model issued from the collisional radiative model CoRaM-N Was $_{2}$ presented. It was implemented in the PINENS code for simulating a Nitrogen non-equilibrium flow past a sphere in atmospheric entry conditions. Aerothermodynamic flow-fields, namely fields of vibrational-state population densities and temperature in the shock layer surrounding the sphere were presented. Obtaining such results in reasonable computational time show that it is possible to predict the vibrational level population distributions throughout an axi-symmetric shock layer with a detailed kinetics model. Comparisons of results obtained with detailed and global models showed a very good agreement for the CORIA model. A focus on the boundary layer was presented. Boltzmann diagrams showed that the Boltzmann distribution of the population densities on the vibrational levels is attained only outside of the boundary layer.

\section{Acknowledgements}

This work was granted access to the High-Performance Computing resources of the "Institut du Développement et des Ressources Informatiques et Scientifiques" (IDRIS) under the allocations 2016-100590 and 2017-100590 made by GENCI (Grand Equipement National du Calcul Scientifique). 


\section{References}

[1] Anderson, J. D., Hypersonic and High Temperature Gas Dynamics, McGraw-Hill, New York, 1989, pp. 483-502.

[2] Armenise, I., Capitelli, M., Colonna, G., and Gorse, C., "Nonequilibrium Vibrational Kinetics in the Boundary Layer of Re-Entering Bodies," Journal of Thermophysics and Heat Transfer, Vol. 10, No. 3, 1996, pp. 397-405. doi: $10.2514 / 3.803$

[3] Gessman, R.J., Laux, C.O., and Kruger, C.H., "Kinetic Mechanisms of Recombining Atmospheric Pressure Air Plasmas," AIAA 97-2364, 28th AIAA Plasmadynamics and Lasers Conference, Atlanta, GA, June 23-25, 1997.

[4] Candler, G.V., Laux, C.O., Gessman, R.J., and Kruger, C.H., "Numerical Simulation of a Nonequilibrium Nitrogen Plasma Experiment," AIAA 97-2365, 28th AIAA Plasmadynamics and Lasers Conference, Atlanta, GA, June 23-25, 1997.

[5] Armenise, I., Capitelli, M., and Gorse, C., "Nitrogen Nonequilibrium Vibrational Distributions and Non-Arrhenius Dissociation Constants in Hypersonic Boundary Layers," Journal of Thermophysics and Heat Transfer, Vol. 12, No. 1, 1998, pp. 45-51. doi: $10.2514 / 2.6300$

[6] Pierrot, L., Laux, C.O., and Kruger, C.H., "Vibrationally-Specific Collisional-Radiative Model for Nonequilibrium Nitrogen Plasmas," AIAA 98-2664, 29th AIAA Plasmadynamics and Lasers Conference, Albuquerque, NM, June 15-18, 1998.

[7] Nagulapally, M., Kolman, D., Candler, G.V., Laux, C.O., Gessman, R.J., and Kruger, C.H., "Numerical Simulation of a Nonequilibrium Air Plasma Experiment," AIAA 98-2665, 29th AIAA Plasmadynamics and Lasers Conference, Albuquerque, NM, June 15-18, 1998.

[8] Pierrot, L., Yu, L., Gessman, R.J., Laux, C.O., and Kruger, C.H., "Collisional-Radiative Modeling of Nonequilibrium Effects in Nitrogen Plasmas," AIAA 99-3478, 30th AIAA Plasmadynamics and Lasers Conference, Norfolk, VA, June 28-July 1, 1999.

[9] Bultel, A., Chéron, B. G., Bourdon, A., Motapon, O., and Schneider, I.F., "Collisional-Radiative Model in Air for Earth Re-Entry Problems," Physics of Plasmas, Vol. 13, No. 4, 2006, Paper 043502. doi:10.1063/1.2194827

[10] Esposito, F., Armenise, I., and Capitelli, M., "N - N2 State to State Vibrational-Relaxation and Dissociation Rates Based on Quasiclassical Calculations," Chemical Physics, Vol. 331, No. 1, 2006, pp. 1-8. doi:10.1016/j.chemphys.2006.09.035

[11] Colonna G., Armenise I., Bruno D., Capitelli M. (1994) 'Reduction of State-to-state Kinetics to Macroscopic Models in Hypersonic Flows', Journal of Thermophysics and Heat Transfer, Vol. 20, No. 3, pp. 477-486.

[12] Armenise, I., Esposito, F., and Capitelli, M., "Dissociation-Recombination Models in Hypersonic Boundary Layer Flows," Chemical Physics, Vol. 336, No. 1, 2007, pp. 83-90.

doi:10.1016/j.chemphys.2007.05.015

[13] Colonna, G., Pietanza, L. D., and Capitelli, M., "Recombination-Assisted Nitrogen Dissociation Rates Under Nonequilibrium Conditions" Journal of Thermophysics and Heat Transfer, Vol. 22, No. 3, 2008, pp. 399-406. doi:10.2514/1.33505

[14] Panesi, M., Magin, T., Bourdon, A., Bultel, A., and Chazot, O., "Fire II Flight Experiment Analysis by Means of a CollisionalRadiative Model," Journal of Thermophysics and Heat Transfer, Vol. 23, No. 2, 2009, pp. 236-248. doi:10.2514/1.39034

[15] Annaloro J., Morel V., Bultel A., Omaly P. (2012) 'Global Rate Coefficients for Ionization and Recombination of Carbon, Nitrogen, Oxygen, and Argon', Physics of Plamas, Vol. 19, No. 7.

[16] Laux, C.O., Pierrot, L., and Gessman, R.J., "State-to-state modeling of a recombining nitrogen plasma experiment," Chemical Physics, Vol. 398, 2012 pp. 46-55.

doi: 10.1016/j.chemphys.2011.10.028.

[17] Panesi M., Jaffe R.L., Schwenke D.W., Magin T.E. (2013) 'Rovibrational Internal Energy Transfer and Dissociation of $\mathrm{N}_{2}(1 \Sigma$ g+)-N(4Su) system in Hypersonic Flows', Journal of Chemical Physics, Vol. 138, No. 4.

[18] Annaloro, J., "Modèles Collisionnels-Radiatifs Appliqués aux Situations d' Entrée Atmosphérique Martienne et Terrestre," Ph.D. Dissertation, CORIA, Univ. de Rouen, France, 2013, (in French). 
[19] Bultel, A., and Annaloro, J., "Elaboration of Collisional-Radiative Models for Flows Related to Planetary Entries into the Earth and Mars Atmospheres," Plasma Sources Science and Technology, Vol. 22, No. 2, 2013, Paper 025008. doi:10.1088/0963-0252/22/2/025008

[20] Annaloro J., Bultel A., Omaly P. (2014) “Collisional-Radiative Modeling Behind Shock Waves in Nitrogen”, J. of Thermophysics and Heat Transfer, Vol. 28, No. 4, pp. 608-622. doi: 10.2514/1.T4263.

[21] Park, C., "Assessment of a Two-Temperature Kinetic Model for Dissociating and Weakly Ionizing Nitrogen,” Journal of Thermophysics, Vol. 2, No. 1, 1988, pp. 8-16.

[22] Park, C., "Review of Chemical-Kinetic Problems of Future NASA Missions, I: Earth Entries," Journal of Thermophysics and Heat Transfer, Vol. 7, No. 3, 1993, pp. 385-398. doi: $10.2514 / 3.431$

[23] Park C., Howe J., Jaffe R., Candler G.V., "Review of chemical-kinetics problems of future NASA missions, 2: Mars entries", Journal of Thermophysics and Heat Transfer, Vol. 8, No. 1, 1994, pp. 9-23. doi: $10.2514 / 3.496$

[24] Cary, B., "Shock-Tube Study of the Thermal Dissociation of Nitrogen,” Physics of Fluids, Vol. 8, No. 1, 1965 , pp. $26-35$. doi:10.1063/1.1761099

[25] Hanson, R. K., and Baganoff, D., "Shock-Tube Study of Nitrogen Dissociation Rates Using Pressure Measurements," AIAA Journal, Vol. 10, No. 2, 1972, pp. 211-215. doi: $10.2514 / 3.50082$

[26] Kewley, D. J., and Hornung, H. G., "Free-Piston Shock-Tube Study of Nitrogen Dissociation," Chemical Physics Letters, Vol. 25, No. 4, 1974, pp. 531-536. doi:10.1016/0009-2614(74)85360-1

[27] Sanders R., Morano E., Druguet M.-C. (1998) 'Multidimensional Dissipation for Upwind Schemes: Stability and Applications to Gas Dynamics', Journal of Computational Physics, Vol. 145, No. 2, pp. 511-537.

[28] Druguet M.-C., Candler G.V., Nompelis I. (2005) 'Effects of Numerics on Navier-Stokes Computations of Hypersonic Double-Cone Flows', AIAA Journal, Vol. 43, No. 3, pp. 616-623.

[29] Cornette, E. S., "Forebody Temperatures and Calorimeter Heating Rates Measured during Project FIRE II Reentry at 11.35 Kilometers per Second," NASA TM-X-1305, 1966.

[30] Landau, L., and Teller, E., “Zur Theorie der Schalldispersion”, Physik Z. Sowjetunion, Vol. 10, No. $34,1936$.

[31] Millikan, R.C., and White, D.R., "Systematics of Vibrational Relaxation,” Chemical Physics, Vol. 39, No. 12, 1963, pp. 3209-3213.

[32] Dunn, M.G., and Kang, S.W., “Theoretical and Experimental Studies of Reentry Plasmas,” NASA-CR-2232, 1973.

[33] Gupta, R.N., Yos, J.M., Thompson, R.A., Lee, K.-P, "A review of reactionrates and thermodynamic and transport properties for an 11-species air model for chemical and thermal nonequilibrium calculations to 30000K", NASA-RP-1232, 1990.

[34] Druguet M.-C., "Prediction of the flow field over an orbiter Entering the Martian Atmosphere", Shock Waves, Vol. 20, No. 3, pp. 251-261.

[35] Wright M.J., Bose D., Candler G.V. (1998) 'Data-Parallel Line Relaxation Method for the Navier-Stokes Equations', AIAA Journal, Vol. 36, No. 9, pp. 1603-1609. 